\title{
Repetitive presuppositions with again: Un-severing the external argument
}

\author{
Josep Ausensi, Jianrong Yu \& Ryan Walter Smith*
}

\begin{abstract}
Since Marantz (1984) and Kratzer (1996), it has been widely accepted in the literature on argument structure that agents are introduced as external arguments via a functional head VOICE through secondary predication, using semantic composition rules like EvENT IDENTIFICATION. The widely cited evidence for such a position is the fact that while internal arguments can condition special semantic interpretations of the surface verb, agents never do. In this paper, we present evidence against such a view, arguing that a well-defined class of verbs can impose intentionality entailments and also require representation of the agent argument internally within their lexical semantics. The crucial empirical evidence we utilize is modification by again, specifically the range of available repetitive presuppositions it can introduce. We show that again behaves differently with respect to how its repetitive presupposition can be satisfied by verbal roots whose agent argument is introduced externally versus verbal roots that must entail intentionality and representation of its agent argument. Together with widely accepted assumptions about the syntax and semantics of again-modification, we argue that not all external arguments can be severed from the verbal root.
\end{abstract}

Keywords. lexical semantics; repetitive presuppositions; external arguments; verbal roots

1. Introduction. Since Marantz (1984) and Kratzer (1996), it has been widely accepted in the literature on argument structure that agents are introduced as external arguments via a functional head VOICE through secondary predication, using semantic composition rules like EvEnT IDENTIFICATION. Evidence for such a position is the fact that while internal arguments can condition special semantic interpretations of the surface verb, agents never do. In this paper, we present evidence against such a view, arguing that a well-defined class of verbs can impose intentionality entailments and also require representation of the external argument internally within their lexical semantics. The crucial empirical evidence we utilize is again-modification, specifically the repetitive presuppositions it introduces. We show again behaves differently in regards to how its repetitive presupposition can be satisfied by verbal roots whose agent argument is introduced externally versus verbal roots that must entail intentionality and representation of its agent argument. Together with widely accepted assumptions about the syntax and semantics of again-modification, we thus argue that not all external arguments can be severed from the verbal root. We further demonstrate using the same diagnostic with again-modification that we can begin to develop a typology of verbal root classes, differing in the two parameters of entailing intentionality and introducing their agent arguments internally.

This paper is organized as follows. Section 2 provides the basic theoretical backdrop for the hypothesis that agents are introduced externally, as well as recent work that argues for a

*We thank Andrew Koontz-Garboden, Martina Faller, John Beavers, Jon Nissenbaum, Chris Davis, Michael Yoshitaka Erlewine, and Jian Gang Ngui for their helpful comments and questions in the process of preparing for this paper and during the oral presentation at the annual meeting. Authors: Josep Ausensi, Universitat Pompeu Fabra (josep.ausensi@upf.edu), Jianrong Yu, The University of Arizona (jianrongyu@email.arizona.edu) \& Ryan Walter Smith, The University of Arizona (ryanwaltersmith@email.arizona.edu). 
more nuanced view that perhaps only some kinds of verbal roots introduce their agent arguments externally, using again-modification as a crucial diagnostic (Bale 2007). Section 3 provides the main empirical data in regards to the repetitive presupposition introduced by again with a well-defined class of verbal roots, illustrating that the ways in which again's repetitive presupposition can be satisfied suggests that these verbal roots must introduce semantic restrictions on their external arguments as well as introduce them internally. Section 4 formalizes these empirical observations into an explicit semantics for different classes of verbal roots, arguing that different verbal root classes can vary in terms of the two conditions of entailing intentionality and representing their agent argument internally. Section 5 points out some future directions of research and concludes.

\section{On external arguments.}

2.1. SEVEring the eXternal ARgument. Marantz (1984) observes that internal arguments can and often condition special semantic interpretations of a verb while external arguments almost never do. We use his examples with kill as an illustration.

(1) a. kill a cockroach

b. kill a conversation

c. kill an evening watching tv

d. kill a bottle (i.e. empty it)

e. kill an audience (i.e. wow them)

As Kratzer (1996; p.114) illustrates, these special intepretations are not limited to completely frozen idiom chunks. For example, kill an evening can have variations of the following, where kill is still conditioned to have the special interpretation of 'wasting time'.

(2) a. kill every evening (that way)

b. kill an evening (reading old Gazettes)

c. kill a lovely morning (paying overdue bills)

Kratzer (1996) argues against treating these different meanings of kill as being instances of homophonous words with different meanings, and that meanings like 'waste time' arise because this meaning is a partial function defined only when the internal argument denotes a time interval. She argues that if this is the correct approach to capturing the special interpretations conditioned by the internal argument, there is no principled reason why the external argument cannot do so; one can easily write partial functions for verb meanings where the agent argument conditions interpretations of a verb. This then means that agent arguments must truly be external to the verb's meaning, such that it is impossible to state restrictions that the agent can impose on the semantics of the verb. ${ }^{1}$ Kratzer (1996) thus proposes that agents are introduced by an inflectional functional head VOICE, via a special semantic composition rule of EVEnt IDENTIFICATION. Adopting fairly standard notations for types, where $e$ is the type of individuals, $s$ the type of events, and $t$ the type of truth values, EVENT IDENTIFICATION takes a function of type $\langle e,\langle s, t>>$ and a function of type $\langle s, t>$ and returns a new function that,

\footnotetext{
${ }^{1}$ See, however, Wechsler (2005) on arguments that this is not true, and restrictions imposed by the external argument can be written at the level of $\mathrm{V}$ or the verbal root before subject-introducing functional heads like $v$.
} 
when supplied with an individual and event argument, returns the conjunction of the result of the two original functions. In this way, EVENT IDENTIFICATION identifies the event variable of the two original functions. On a theory countenancing EVENT IDENTIFICATION, VoICE would have the lexical entry shown below, and combine with a VP via EVENT IDENTIFICATION.

\section{(3) EVEnt IDENTIFICATION:$$
\mathrm{f}_{e, s t}+\mathrm{g}_{s t} \rightarrow \lambda \mathrm{x} . \lambda \mathrm{e} . \mathrm{f}(\mathrm{x})(\mathrm{e}) \wedge \mathrm{g}(\mathrm{e})
$$ \\ $\llbracket$ VOICE $\rrbracket: \lambda x \lambda e \cdot \operatorname{AgEnT}(\mathrm{e})=\mathrm{x}$}

2.2. REPETITIVE PRESUPPOSITIONS WITH again. Bale (2007) argues that while Kratzer's (1996) proposal can be shown to hold for non-stative transitive verbs, it does not seem to hold across all verb classes. He utilizes again-modification as crucial evidence, specifically taking advantage of the fact that again is an event modifier of type $\langle<s, t\rangle,\langle s, t\rangle>$, taking a type $<s, t>$ predicate of events as its argument and returns that exact same event, while introducing a presupposition that a previous event of the same type must have happened (Bale 2007; von Stechow 1995, 1996; Beck \& Johnson 2004; a.o.). We provide a modified version of Bale's (2007; p.451) semantics for again below.

【again $\rrbracket \mathrm{P}(\mathrm{e})$ is defined iff $\exists \mathrm{e}^{1} \exists \mathrm{e}^{2}\left[\mathrm{e}^{1} \prec \mathrm{e}^{2} \prec \mathrm{e} \& \mathrm{P}\left(\mathrm{e}^{1}\right) \& \neg \mathrm{P}\left(\mathrm{e}^{2}\right)\right]$. When defined, $\llbracket$ again $\rrbracket \mathrm{P}(\mathrm{e})=\mathrm{P}(\mathrm{e})$.

Given these assumptions about the semantics of again, Bale (2007) shows that Kratzer's (1996) hypothesis about agents being external arguments of a verb holds true for non-stative transitive verbs. The crucial observation comes from what he calls subjectless presuppositions, where again's presupposed prior event can be satisfied by an event of the same type but crucially with a different agent argument. We illustrate with the non-stative transitive verb hit (Bale 2007; p.464 example (29a)).

(6) Context: Seymour's dryer broke. He called a repairwoman who simply hit the dryer until it started working. The dryer broke down two days later. So...

Seymour hit the dryer again.

Under Kratzer's (1996) proposal, the fact that again's presupposition is satisfied by an event with a different agent is predicted; since again adjoins to the VP below the agent-introducing VOICE head, the presupposition need only contain the event denoted by the verbal root and its internal argument, imposing no requirements on its agent argument. Thus, a previous event with a different agent can satisfy again's presupposition.

On the other hand, Bale shows that stative transitive as well as intransitive verbs, whether unergative or unaccusative, do not tolerate a subjectless presupposition with again-modification. This is unexpected if the agent argument of an unergative is also introduced externally, as Kratzer's (1996) proposal would suggest. We illustrate using examples with love, arrive, and run (Bale 2007; examples (47a), (54), and (55)). ${ }^{2}$

\footnotetext{
${ }^{2}$ Bale (2007) dedicates a significant amount of space to discussing possible counterexamples, arguing that they do not undermine the generalization of a contrast between non-stative transitive verbs and the other verb types. The interested reader is invited to consult those specific sections of Bale's article for details and discussion.
} 
(7) Context: Seymour's mother loved Frank, although she was the only one who did. After a while she no longer cared for him. However, Seymour became attached to the man, and developed strong feelings for him after his mother's love subsided. So...

\section{\# Seymour loved Frank again.}

(8) Context: Seymour's wife was the first person ever to arrive at the new airport. Then a week later...

\section{\# Seymour arrived again.}

(9) Context: Last week, Jon's wife ran all morning. Then after she got home, Jon was able to do some exercise. So...

\section{\# Jon ran again.}

If non-stative transitive verbs allow for a subjectless presupposition because there is a position again can adjoin to which excludes the agent argument, then non-stative transitives and intransitives must not have such a position available for again-modification. That is, the VP that again adjoins to must not only contain the verbal root and its internal argument, but also its external argument. Bale (2007) thus argues that while non-stative transitive verbal roots are functions from individuals to predicates of events whose agents must be introduced externally through secondary predication, stative transitive verbs must be functions from individuals to individuals to predicates of events, while intransitives must be functions from individuals to predicates of events. We illustrate with lexical entries for hit, love, arrive, and run.
a. $\llbracket \sqrt{ } \operatorname{HIT} \rrbracket: \lambda x \lambda$ e.Hit(e) $\wedge \operatorname{THEME}(\mathrm{e})=\mathrm{x}$
b. $\llbracket \sqrt{ } \operatorname{LOVE} \rrbracket: \lambda y \lambda x \lambda e \cdot \operatorname{Love}(\mathrm{e}) \wedge \operatorname{ExPERIENCER}(\mathrm{e})=\mathrm{x} \wedge \operatorname{THEME}(\mathrm{e})=\mathrm{y}$
c. $\llbracket \sqrt{ }$ Arrive $\rrbracket: \lambda x \lambda$ e.Arrive(e) $\wedge \operatorname{Theme}(e)=x$
d. $\llbracket \sqrt{ } \operatorname{Run} \rrbracket: \lambda x \lambda$ e.Run(e) $\wedge \operatorname{AgEnT}(\mathrm{e})=\mathrm{x}$

3. Different classes of non-stative transitive verbs. While Bale (2007) uses again-modification to illustrate that non-stative transitive verbs associate with their external arguments differently from stative transitive and intransitive verbs, we show in this section that even within the class of transitive verbs, one is able to distinguish different sub-classes that associate with their agent arguments internally rather than externally. ${ }^{3}$ We illustrate with again-modification, showing that there is a contrast in how sub-classes allow for again's presupposition to be satisfied in regards to entailment of volition and intentionality of the agent, as well as with prior events with different agents.

3.1. ENTAILING InTENTIONALiTy. The first observation is that while certain transitive verbal roots like kill, shatter, and break ( $\sqrt{ }$ KILL-type) allow for their external arguments to be inanimate, unintentional causers, other verbal roots like murder, slay, massacre, slaughter (Ausensi 2019) ( $\sqrt{ }$ MURDER-type) roots disallow them. Similarly, $\sqrt{ }$ KILL-type roots allow for the event to have happened by accident without intention, while $\sqrt{ }$ MURDER-type roots do not (Folli \& Harley 2005, a.o.).

\footnotetext{
${ }^{3}$ In fact, Smith and Yu (In prep) show that even intransitive but optionally transitive unergative verbs allow for subjectless presuppositions when these unergative verbs have internal arguments or when they combine with prepositional phrases denoting directed motion.
} 
(11) a. John killed the zombies by accident/unintentionally.

b. The bomb killed all the zombies.

c. The explosion killed all the zombies.

d. That machine gun killed all the zombies.

(12) a. John murdered/massacred/slaughtered/slew the monsters (\#unintentionally/\#but didnt intend to/\#accidentally)

b. \#The explosion/\#The gun/\#The bomb murdered/slaughtered/slew/massacred the monsters.

Kratzer's (1996) hypothesis explains the lack of restrictions with $\sqrt{ }$ KILL-type roots, since agents are introduced externally and thus the verbal root cannot impose any semantic requirements on the agent. However, it does not explain $\sqrt{ }$ MURDER-type roots, which do impose requirements on the kinds of agents that can be introduced. Interestingly, these contrasts are reproduced in the way again's presupposition can be satisfied when these two different classes of verbal roots are modified. With $\sqrt{ }$ KILL-type roots, the presupposed prior event can be an event carried out unintentionally by an animate agent or by an inanimate causer. On the other hand, $\sqrt{ }$ MURDER-type roots systematically disallow such events as the presupposed prior event of again (see Ausensi To appear).

(13) Noah killed the monsters again.

a. oK He caused the monsters to become dead by intentionally killing them again.

b. oK He caused the monsters to become dead by intentionally killing them again but last time they were killed unintentionally/by accident/by the bomb/by the explosion/by the gun.

(14) Noah murdered/slaughtered/slew/massacred the monsters again.

a. oK He caused the monsters to become dead by intentionally killing them again.

b. \# He caused the monsters to become dead by intentionally killing them again but last time they were killed unintentionally/by accident/by the explosion/by the bomb/by the gun.

Taking the adjunction site of again to be a predicate of events and its presupposition to tell us the semantic content of that particular event denoted by the constituent it adjoins to, this indicates that the constituent that again adjoins to excludes any entailments of intentionality for $\sqrt{ }$ KILL-type roots, subsequently imposing no restrictions on how again's presupposed event is satisfied. On the other hand, the contrast shown above indicates that the constituent again adjoins to with $\sqrt{ }$ MURDER-type roots must entail intentionality on the part of the external argument and thus must somehow be encoded within these verbal roots themselves.

It is important to note that while $\sqrt{ }$ MURDER-type roots seem to entail intentionality, the entailment applies only to the intention of the external argument in carrying out a killing event. In particular, $\sqrt{ }$ MURDER-type roots entail that the external argument must have the intention of carrying out the event denoted by the verbal root, but need not result in the intended entity 
becoming the holder of the result state. ${ }^{4}$ This can be brought out by the following context, using murder as an example.

(15) Context: Noah wanted to kill the monsters using a bow and arrow. But he's such a bad shot that he shot the arrow at the humans instead of the monsters so...

Noah murdered the humans instead.

This observation will be an important consideration in formulating the exact condition on the entailment of intentionality for $\sqrt{ }$ MURDER-type roots and the scope it has over sub-parts of the event, which we provide in section 4.

3.2 The Availability of Subjectless Presuppositions. Parallel to the contrast between non-stative transitive and stative transitive and intransitive verbs, we observe the same contrast in the availability of subjectless presuppositons between $\sqrt{ }$ KILL-type and $\sqrt{ }$ MURDERtype verbal roots, even if they are both transitive verbs and thus should both allow subjectless presuppositions under Bale's (2007) generalization. Rather, $\sqrt{ }$ KILL-type verbal roots allow a presupposed prior event carried out by a different agent (Bale 2007; example (33a)), while $\sqrt{ }$ MURDER-type verbal roots systematically disallow them.

(16) Context: In a Hollywood monster movie, Seymour's father killed the zombie. But, being a Hollywood movie, of course they came back to life. But in the end...

Seymour killed the zombie again.

(17) ConTEXT: In a Hollywood monster movie, Seymour's father murdered the zombie. But, being a Hollywood movie, of course they came back to life. But in the end... \# Seymour murdered the zombie again.

Again, adopting Kratzer's (1996) proposal we can straightforwardly predict the lack of a subjectless presupposition for $\sqrt{ }$ KILL-type verbal roots if again adjoins to the VP prior to combining with the agent-introducing VOICE head. However, it would be mysterious why $\sqrt{ }$ MURDER-type verbal roots disallow them in the face of Bale's (2007) generalization, since the same adjunction site excluding the agent should also be available for again to produce a subjectless presupposition.

3.3. ON FLAVORS OF LitTLE $v$. At this point it may be worth mentioning a slightly different approach to disentangling the animacy and intentionality requirements on agent arguments from the VOICE head that syntactically introduces it. An influential approach that attempts to do this is that of Folli and Harley (2005), who argue for different 'flavors' of verbalizing heads that verbalize an acategorial root in the Distributed Morphology tradition (Halle \& Marantz 1993). Specifically, they distinguish between $v_{\text {CAUSE }}$ and $v_{\text {DO }}$, which for them is the locus of animacy and intentionality. $v_{\text {CAUSE }}$ simply expresses causative semantics, imposing no semantic requirement of animacy on the external argument. On the other hand, $v_{\mathrm{DO}}$ imposes an animacy requirement and requires the external argument to be interpreted thematically as an agent. Distinguishing between a verbalizing little $v$ and the external argument-introducing

\footnotetext{
${ }^{4}$ We thank Jian Gang Ngui for pointing this out during the question period of the oral presentation at the annual meeting.
} 
head VoICE (contra theories that suggest little $v$ introduces the external argument like Chomsky 1995), this means that the argument introduced by VOICE must be compatible with the semantic requirements imposed by the flavor of little $v$ present in the structure. For them then, $\sqrt{ }$ KILL-type roots are compatible with both $v_{\text {CAUSE }}$ and $v_{\text {DO }}$ as a matter of semantic selection, explaining why they allow both inanimate causers and animate agents introduced by VOICE. $\sqrt{ }$ MURDER-type roots then must be selected only by $v_{\text {DO }}$, conditioning VOICE to introduce an external argument that must be interpreted thematically as an agent.

Despite their proposal being able to dissociate semantic restrictions on the external argument from the functional head introducing the external argument itself, we nevertheless do not think Folli and Harley's (2005) proposal is adequate to capture the observations with againmodification we described, specifically with $\sqrt{ }$ MURDER-type roots. Consider first $\sqrt{ }$ KILL-type

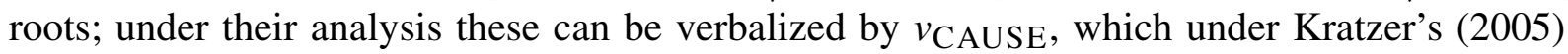
formulation is a relation between two event predicates of type $\langle s, t>$. This means that before combining with $v_{\text {CAUSE }}$, there is a constituent of type $<s, t>$ that again can adjoin to, producing a presupposition that need not include the causer external argument. While Folli and Harley (2005) do not give an explicit semantics for $v_{\mathrm{DO}}$, we might assume that with $\sqrt{ }$ KILLtype roots the constituent $v_{\text {DO }}$ verbalizes should be semantically identical as when verbalized by $v_{\text {CAUSE }}$, and thus available for again-modification. As predicted, whether the subject argument is an animate and intentional agent or inanimate causer, there are no restrictions imposed on again's presupposition since it adjoins before the verbalizing heads are introduced.

The same reasoning, however, runs into trouble with $\sqrt{ }$ MURDER-type roots verbalized only by $v_{\mathrm{DO}}$. If $v_{\mathrm{DO}}$ is also a relation between two event predicates of type $\langle s, t>$ regardless of how the animacy requirement is encoded in the semantics, then the constituent it verbalizes should also be of type $<s, t>$ available for again-adjunction, predicting that they should also allow for subjectless presuppositions and not require again's presupposition to be satisfied by an intentional agent. As we have seen in the previous sections, this prediction is not borne out and $\sqrt{ }$ MURDER-type roots systematically disallow them. That Folli and Harley's (2005) analysis makes the wrong predictions even when they attempt to dissociate animacy requirements from VOICE shows that the intentionality entailments as well as representation of the agent argument must be truly internal to the lexical semantics of $\sqrt{ }$ MURDER-type roots, while $\sqrt{ }$ KILL-type roots must lack internal representation of them. We turn now to a formalization of the lexical semantics of these two classes of verbal roots in the next section.

\section{Classes of verbal roots.}

\subsection{The SEMANTICS OF $\sqrt{ }$ KILL-TYPE AND $\sqrt{ }$ MURDER-TYPE ROOTS. The main empirical} observation to be accounted for from the previous section is that there is a class of non-stative verbal roots which require intentionality and their agent argument to be part of their lexical semantics. We propose that apart from the explicit representation of the external argument as a thematic role, the entailment of intentionality is encoded as a modal relation between an entity and a proposition such that for all worlds compatible with the entity's intentions, the entity is the causer of the causing event resulting in a result state. We present the lexical entries for $\sqrt{ }$ KILL-type and $\sqrt{ }$ MURDER-type roots below, adopting Beavers \& Koontz-Garboden (in press) lexical entry for kill, and omitting world variables for perspicuity. Note that $\mathrm{P}$ is a variable for a state that will be root-specific; for kill and murder, for example, $\mathrm{P}$ will be a state DEAD such that the entity is in a state of death. 


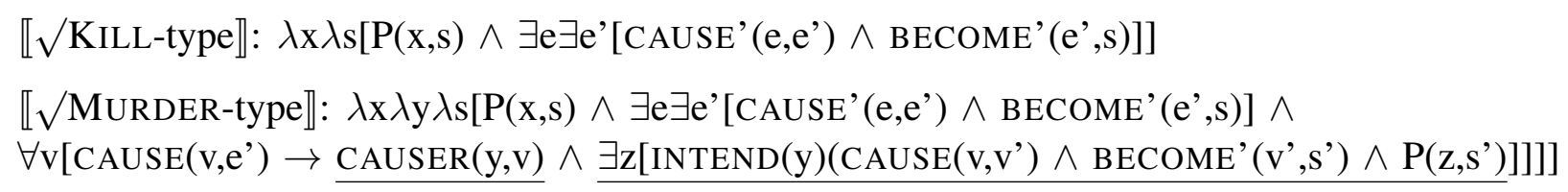

The key difference, indicated by the underlined portions of the lexical entry for $\sqrt{ }$ MURDERtype roots, is that it contains a causer argument and the modal INTEND relation. The INTEND relation has a result state that holds of an existentially quantified entity which crucially may be different from the entity in the world of evaluation, accounting for examples like (15), where the actual entity being affected by the event may not be the entity the causer intended to affect. We can see now how these lexcial entries account for the again-modification facts discussed previously. With $\sqrt{ }$ KILL-type roots, again can adjoin once they have combined with an entity that is the holder of the result state. There is no entailment of intentionality, nor does the root directly take a causer argument, and therefore there is neither an intentionality requirement nor a requirement that the causer argument be identical to that of the asserted event imposed on the event presupposed by again. $\sqrt{ }$ MURDER-type roots can combine with again only after both of its entity arguments have combined with them, with the entities identifying the holder of the result state as well as the causer of the event. Furthermore, the constituent again adjoins to contains the INTEND relation, and thus the presupposed prior event must have been caused by the same individual as the asserted event, and that individual must have intended to cause the presupposed event.

A brief clarification might be in order here. Notice that both $\sqrt{ }$ KILL-type and $\sqrt{ }$ MURDERtype roots are predicates of states once their entity arguments have combined. However, the lexical entries we adopt from Beavers \& Koontz-Garboden (in press) nonetheless predict that we should not be able to obtain the well-known and well-discussed restitutive reading with verbs like kill, as the lexical entry entails both an existentially quantified causing and changeof-state event. In that regard, the analysis here is consistent with Fodor (1970), an early argument against decomposing kill into more primitive meaning components like CAUSE to DIE in the Generative Semantics tradition, but not with analyses like Harley's (2012), who provides independent explanations for Fodor's (1970) arguments. While we adopt an analysis that predicts such restitutive readings to be unavailable, we actually find that with the right contexts, a restitutive reading where a previous result state of being dead is repeated to be available with verbs like kill. We adopt the lexical entry in (18) based on Beavers and Koontz-Garboden Beavers \& Koontz-Garboden (in press) for concreteness and refrain from making any claims about the availability of restitutive readings for verbs like kill. Regardless, the exact approach taken to the decomposition of kill ultimately has no bearing on the analysis of $\sqrt{ }$ MURDERtype roots, as verbs based on such roots do not permit a restitutive reading in the first place, as (20) shows.

(20) Context: A group of monsters dies of natural causes. However, they are raised from the dead by a powerful necromancer. Seeing the havoc the resurrected monsters are wreaking, Seymour takes up his gun and mows them down.

\section{\# Seymour murdered the monsters again.}

As stated above, this unavailability falls out naturally from our analysis: there is no constituent of the appropriate type to be taken as an argument by again that excludes an entailment of the existence of an event causing the death of the monsters with Seymour as agent. 
4.2. TOWARDS A TYPOLOGY OF VERBAL ROOTS. Given the analysis of $\sqrt{ }$ KILl-type and $\sqrt{ }$ MURDER-type roots, where the main difference lies in whether or not the causer argument is represented and whether intentionality on the part of the causer argument is entailed, one might wonder if there might be verbal root classes that either represent the causer argument without encoding intentionality or vice versa. We might also wonder whether there are verbal root classes that impose other kinds of semantic requirements apart from representing the causer argument and entailing intentionality. We illustrate that we can begin to develop a typology with two other classes of verbal roots.

The first involves other manner-of-killing verbs like guillotine, drown, hang etc. These are similar to verbs like kill and murder, as discussed by Beavers and Koontz-Garboden (2012; In press). For example, they give the lexical entry for guillotine as below.

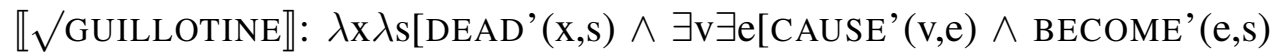

$$
\begin{aligned}
& \left.\left.\left.\left.\wedge \forall v^{\prime} \text { [CAUSE' }\left(\mathrm{v}^{\prime}, \mathrm{e}\right) \rightarrow \text { GUILLOTINING'( } \mathrm{v}^{\prime}\right)\right]\right]\right]
\end{aligned}
$$

As with $\sqrt{ }$ KILL-type roots, these verbal roots entail a causing and change-of-state event and do not represent a causer argument and encode intentionality as do $\sqrt{ }$ MURDER-type roots. Crucially, they differ from both $\sqrt{ }$ KILL-type and $\sqrt{ }$ MURDER-type roots in that they entail that the causing event must be of a specific type, in this case a guillotining. Thus, verbs like guillotine, by virtue of being a predicate of states once it has combined with its entity argument and also entailing a particular kind of causing event, is a mixed-manner-result verb in Beaver's and Koontz-Garboden's (2012) typology of manner versus result roots. We note here that the given lexical entry makes the right predictions in regards to again-modification; verbs like guillotine allow subjectless presuppositions as in (22), do not require the presupposed prior event to be carried out intentionally in (23), but require the presuppsoed prior event to be of the same kind as the asserted event in (24).

(22) Context: John guillotined the zombie. The zombie came back to life and reattached its head.

\section{Mary guillotined it again.}

(23) Context: The zombie was guillotined by the blade by accident. It came back to life and reattached its head.

Mary guillotined it again.

(24) CONTEXT: Mary hanged the zombie to escape from it. It came back to life after it was released from the rope.

\section{\# Mary guillotined it again.}

A second class of verbal roots that can be identified are those that entail intentionality but do not represent a causer argument internally. These form a class that can be described as manner-of-stealing verbs like $m u g$, rob etc. (Ausensi, in prep). As shown below, verbs like mug disallow modification with accidentally or unintentionally, but allow subjectless presuppositions with again-modification.

(25) \# John mugged Tim by accident/unintentionally.

(26) Context: John mugged Tim in the park. Tim kept walking, and...

\section{Mary mugged him again.}


This thus suggests that we may isolate different verbal root classes based on the two parameters of whether they represent the causer argument intentionally and if they entail intentionality. We have seen three of the four possible combinations of these two parameters: $\sqrt{ }$ KILL-type roots which have neither, $\sqrt{ }$ MURDER-type roots which encode both, and mannerof-stealing verbs which entail intentionality but do not represent a causer argument. It is an empirical question whether there are verbal roots that fall into the fourth logical possibility, where they represent a causer argument but do not entail intentionality. We leave this for future inquiry.

5. Conclusion. In this paper, we argued against severing all external arguments from their verbs (Kratzer 1996), arguing following Bale (2007) that there are distinct classes of verbal roots whose agent arguments cannot be severed from the verbal roots and also impose semantic requirements on their external arguments. The crucial evidence we use to argue for such a position come form again-modification, specifically whether particular classes of verbal roots allow for again's presupposition to be satisfied by a non-intentional event or an event that contains a different agent argument. Based on this diagnostic, we were able to argue for at least four distinct classes of roots based on how they behave in regards to again-modification: $\sqrt{ }$ KILL-type roots which do not represent the causer argument or entail intentionality, $\sqrt{ }$ MURDERtype roots which represent their causer argument and entail intentionality, $\sqrt{ }$ GUILLOTINE-type roots which do not represent the causer argument and do not entail intentionality but have manner entailments, and manner-of-stealing verbs which entail intentionality but do not represent a causer argument. Overall, we can see the utility of using again-modification to probe the internal semantics of verbal roots as its adjunction position and presupposition can help to identify the semantic content that needs to be contained within the constituent it adjoins to.

One further question remains. We have so far remained agnostic as to how the verbal roots are treated in the syntax, in particular if there are templatic meanings like CAUSE and BECOME introduced by functional little $v$ heads within the syntax even if some verbal roots already entail these (Beavers \& Koontz-Garboden 2017, In press), and whether causer arguments are still introduced by heads like VOICE even if the verbal root explicitly represents its causer argument. One might imagine, for example, that the causer argument within a verbal root's lexical semantics is simply represented using a variable, and heads like VOICE then introduce an external argument which binds that variable. We leave the possibility and implications of such an analysis for future inquiry.

\section{References}

Ausensi, Josep. 2019. Agent entailments induce manner properties: Evidence from verbs of killing. In Van Alem Astrid, Anastasiia Ionova \& Cora Pots (eds.), Proceedings of the 27th Conference of the Student Organization of Linguistics in Europe. 118-134. Leiden University Centre for Linguistics.

Ausensi, Josep. In prep. On (im)possible verb meanings: The role of intentionality. Unpublished manuscript, Universitat Pompeu Fabra.

Ausensi, Josep. To appear. Agent entailments in the semantics of roots. In Ryan Budnick \& Nari Rhee (eds.), University of Pennsylvania Working Papers in Linguistics, vol. 26 1, Penn Graduate Linguistics Society.

Bale, Alan. 2007. Quantifiers and verb phrases: An exploration of propositonal complexity. Natural Language \& Linguistic Theory 25. 447-483. https://doi.org/10.1007/ s11049-007-9019-8. 
Beavers, John \& Andrew Koontz-Garboden. 2012. Manner and result in the roots of verbal meaning. Linguistic Inquiry 43(3). 331-369. https://doi.org/10.1162/LING_a_00093.

Beavers, John \& Andrew Koontz-Garboden. 2017. The semantic contribution of idiosyncratic roots in ditransitive verbs. In Cole Brendel, Aron Kaplan, Abby Kaplan, Miranda McCarvel, Jeff Pynes \& Ed Rubin (eds.), Proceedings of the 34th West Coast Conference on Formal Linguistics. 70-80. Cascadilla Proceedings Project, Somerville, MA.

Beavers, John \& Andrew Koontz-Garboden. In press. The meaning of verbal roots and the roots of verbal meaning. Oxford: Oxford University Press.

Beck, Sigrid \& Kyle Johnson. 2004. Double objects again. Linguistic Inquiry 35(1). 97-123. https://doi.org/10.1162/002438904322793356.

Chomsky, Noam. 1995. The Minimalist Program. Cambridge, MA: MIT Press.

Fodor, Jerry. 1970. Three reasons for not deriving kill from cause to die. Linguistic Inquiry 1(4). 429-438. http://www.jstor.org/stable/4177587.

Folli, Raffaella \& Heidi Harley. 2005. Flavors of $v$. In Paula Marie Kempchinsky \& Roumyana Slabakova (eds.), Aspectual inquiries. 99-120. Springer, Dordrecht.

Halle, Morris \& Alec Marantz. 1993. Distributed Morphology and the pieces of inflection. In Ken Hale \& Samuel Jay Keyser (eds.), The view from building 20: Essays in honor of Sylvain Bromberger. 111-176. Cambridege, MA: MIT Press.

Harley, Heidi. 2012. Lexical decomposition in modern syntactic theory. In Wolfram Hinzen, Edouard Machery \& Markus Werning (eds.), The Oxford handbook of compositionality. 328-350. Oxford: Oxford University Press.

Kratzer, Angelika. 1996. Severing the external argument from its verbs. In Laurie Ann Zaring \& Johan Rooryck (eds.), Phrase structure and the lexicon. 109-137. Dordrecht: Kluwer.

Kratzer, Angelika. 2005. Building resultatives. In Claudia Maienborn \& Angelika W“ollstein (eds.), Event arguments: Foundations and applications. 177-212. T"ubingen: Niemayer.

Marantz, Alec. 1984. On the nature of grammatical relations. Cambridge, MA: MIT Press.

Smith, Ryan Walter \& Jianrong Yu. In prep. Subjectless presuppositions and the semantics of verbal roots. Paper to be presented at the 38th meeting of the West Coast Conference on Formal Linguistics.

von Stechow, Arnim. 1995. Lexical decomposition in syntax. In Urse Egli, Peter E. Pause, Christoph Shwarze, Armin von Stechow \& Götz Weinold (eds.), The lexicon in the organization of language, 81-118. Amsterdam and Philedelphia: John Benjamins.

von Stechow, Arnim. 1996. The different readings of wieder 'again': A structural account. Journal of Semantics 13(2). 87-138. https://doi.org/10.1093/jos/13.2.87.

Wechsler, Stephen. 2005. What is right and wrong about little $v$. In Mila DimitrovaVulchanova \& Tor A. Åfarli (eds.), Grammar and beyond-Essays in honour of Lars Hellan, 179-195. Oslo: Novus Press. 